\title{
Relevance of apolipoprotein E4 for the lipid profile of Brazilian patients with coronary artery disease
}

D.R.S. Souza ${ }^{1}$, L. Nakachima ${ }^{1}$, R.B. Biagioni ${ }^{1}$, M.A. Nakazone ${ }^{1}$, M.A.S. Pinhel ${ }^{1}$, D.M. Trindade ${ }^{1}$, V.T. Mafra ${ }^{1}$, L.H.B. Tácito ${ }^{2}$, J.F.V. Martin ${ }^{2}$, S. Pinheiro Júnior ${ }^{1}$ and A.C. Brandão ${ }^{1}$
1Departamento de Biologia Molecular, ²Departamento de Clínica Médica, Faculdade de Medicina de São José do Rio Preto, São José do Rio Preto, SP, Brasil
Correspondence

D.R.S. Souza

Departamento de Biologia Molecular

Faculdade de Medicina de São José do Rio Preto

Av. Brigadeiro Faria Lima, 5416 15090-000 São José do Rio Preto, SP Brasil

Fax: +55-11-3201-5700

E-mail: doroteia@famerp.br

Publication supported by FAPESP.

Received October 6, 2005

Accepted November 6, 2006

...............

\begin{abstract}
Apolipoprotein E (apoE - $\varepsilon 2, \varepsilon 3, \varepsilon 4$ alleles) plays a role in the regulation of lipid metabolism, with the $\varepsilon 4$ considered to be a risk factor for coronary artery disease (CAD). We aimed to evaluate the apoE polymorphisms in Brazilians with $\mathrm{CAD}$ and their influence on the lipid profile and other risk factors (hypertension, diabetes mellitus, smoking). Two hundred individuals were examined: 100 patients with atherosclerosis confirmed by coronary angiography and 100 controls. Blood samples were drawn to determine apoE polymorphisms and lipid profile. As expected, the $\varepsilon 3$ allele was prevalent in the CAD (0.87) and non-CAD groups $(0.81 ; \mathrm{P}=0.099)$, followed by the $\varepsilon 4$ allele ( 0.09 and 0.14 , respectively; $\mathrm{P}=0.158)$. The $\varepsilon 3 / 3$ (76 and $78 \%$ ) and $\varepsilon 3 / 4$ (16 and $23 \%$ ) were the most common genotypes for patients and controls, respectively. The lipid profile was altered in patients compared to controls $(\mathrm{P}<0.05)$, independently of the $\varepsilon 4$ allele. However, in the controls this allele was prevalent in individuals with elevated LDL-cholesterol levels only (odds ratio $=2.531 ; 95 \% \mathrm{CI}=$ 1.028-6.232). The frequency of risk factors was higher in the CAD group $(\mathrm{P}<0.05)$, but their association with the lipid profile was not demonstrable in $\varepsilon 4$ carriers. In conclusion, the $\varepsilon 4$ allele is not associated with $\mathrm{CAD}$ or lipid profile in patients with atherosclerosis. However, its frequency in the non-CAD group is associated with increased levels of LDL-cholesterol, suggesting an independent effect of the $\varepsilon 4$ allele on lipid profile when the low frequency of other risk factors in this group is taken into account.
\end{abstract}

Key words

- Apolipoprotein E polymorphism

- Coronary artery disease

- Lipid profile

\section{Introduction}

Apolipoprotein E (apoE), identified at the beginning of the 1970's, has been associated with coronary artery disease (CAD), as well as other illnesses including cerebrovascular, peripheral artery and neurodegenera- tive diseases such as late-onset Alzheimer's disease (1-8), as a result of the allelic variations of the $A P O E$ gene ( $\varepsilon 2, \varepsilon 3$, and $\varepsilon 4)$ (3). ApoE polymorphisms regulate changes in lipid metabolism, platelet aggregation and processes of oxidative stress (9). However, their influence on serum lipids in patients 
with CAD is of particular interest.

The apoE isoforms differ in their affinity for specific receptors including the low-density lipoprotein (LDL) receptor and LDL receptor-related protein. ApoE4 has a slightly greater affinity for these receptors compared to apoE3, while apoE2 rarely binds, having a binding capacity of less than $2 \%$ of that of apoE3 (10). Hence, apoE polymorphisms are related to the concentration of lipids and lipoproteins in the circulation of human populations, accounting for 4 to $15 \%$ of the variations in the serum levels of the LDL cholesterol fraction (LDLc) (6). The $\varepsilon 4$ allele (E3/4 and E4/4 phenotypes) has been associated with elevated serum LDLc levels and consequently it is considered to be a risk factor for $\mathrm{CAD}$, while the $\varepsilon 2$ allele (E2/2 and $\mathrm{E} 2 / 3)$ seems to be related to low levels of LDLc and increased concentrations of plasma triglycerides (TG) and lipoprotein remnants (3).

High LDLc and total cholesterol (TC) values were observed in decreasing order in individuals with phenotypes $\mathrm{E} 2 / 3<\mathrm{E} 3 / 3<$ $\mathrm{E} 4 / 3<\mathrm{E} 4 / 4$ (11). Moreover, the high frequency of the $\varepsilon 4$ allele associated with increased levels of TG and decreased highdensity lipoprotein cholesterol (HDLc) levels suggested its role as one of the factors contributing to the high mortality rate from cardiovascular disease in Australian aborigines (12). Furthermore, a report stated that genotypes with the $\varepsilon 2$ and $\varepsilon 4$ alleles are more commonly seen at health centers that treat lipid-based diseases compared to the $\varepsilon 3$ allele (13). The $\varepsilon 4$ allele is also related to an increased risk of silent myocardial infarction induced by exercise in apparently healthy normolipidemic elderly men (14). A study of possible genetic markers in Brazilian women demonstrated an association of the apoE and apoB polymorphisms and those of the LDL receptor gene with CAD (4). However, in Chinese patients, the apoE allelic frequencies were similar in patients and controls (15). In Italians, the $\varepsilon 4$ allele was not correlated to an increase in risk for acute myocardial infarction in patients with $\mathrm{CAD}$ (16).

Thus, the effect of the apoE polymorphisms on the serum lipid levels is variable. The $\varepsilon 2$ allele showed a positive correlation with lipid levels in an elderly multiethnic population, while the $\varepsilon 4$ allele was not expressed (17), and was not associated with changes in the lipid profile of a rural North American population (18). The extent of atherosclerotic injury in the coronary arteries and aorta and the levels of serum lipids also proved to be unaffected by the apoE genotypes in North Americans (19).

The objective of the present study was to evaluate the allelic and genotypic frequencies for apoE in Brazilian subjects with CAD and non-CAD and their influence on the lipid profile together with other risk factors for the disease.

\section{Material and Methods}

\section{Patients}

A total of 128 male (64\%) and 72 female (36\%) unrelated individuals of mixed ethnicity, representative of Brazilian population, ranging in age from 40 to 78 years were assessed in a case-control type study (20). The individuals were attended at the Hospital of São José do Rio Preto Medical School, São José do Rio Preto, SP, Brazil, and were divided into two groups: CAD group, 100 patients $(60.8 \pm 10.0$ years $)$ with lesions confirmed by coronary angiography, and non-CAD group, 100 individuals $(60.1 \pm 8.8$ years; $P=0.573$ ) with clinical signs suggestive of CAD and with an indication for coronary angiography during the diagnostic procedure but with proved absence of coronary obstruction.

The study was approved by the Research Ethics Committee of the São José do Rio Preto Medical School, SP, Brazil. All individuals signed written consent forms before being included in the study. 
ApoE polymorphism, lipid profile and personal antecedents

The study of the apoE polymorphisms involved DNA extraction, amplification by the polymerase chain reaction, enzymatic digestion with $H h a \mathrm{I}$, and $6 \%$ polyacrylamide gel electrophoresis with ethidium bromide staining (21).

The lipid profile was analyzed when patients were not taking lipid-reducing medications. Serum TG and TC levels were determined by enzymatic colorimetric methods (22). The serum levels of HDLc were analyzed by precipitation with dextran-magnesium chloride (23) and the Friedewald formula was used to calculate LDLc and VLDLc levels for TG of less than $400 \mathrm{mg} /$ $\mathrm{dL}$. The reference values used were those recommended by the III Brazilian Guidelines on Dyslipidemias and Guidelines of Atherosclerosis Prevention from the Atherosclerosis Department of Sociedade Brasileira de Cardiologia (24).

Both groups were evaluated with respect to the prevalence of hypertension, diabetes mellitus and smoking. Individuals were considered to be hypertensive if arterial blood pressures were equal to or higher than 140/ $90 \mathrm{mmHg}$ for systolic and diastolic blood pressures, respectively, or if they were taking anti-hypertensive drugs. Diabetes mellitus was reported by patients diagnosed by a physician or whose laboratory examinations showed fasting blood sugar levels higher than $126 \mathrm{mg} / \mathrm{dL}$ (25). Smokers were those individuals who smoked at least one cigarette per day or who had stopped smoking within the previous two years. These risk factors were also studied considering the apoE polymorphisms and the lipid profile.

\section{Statistical analysis}

The allelic and genotypic frequencies, calculated by counting the alleles, were compared between groups using the Fisher exact test or the chi-squared test, that was used also to compare the observed and expected genotypic frequencies in order to test HardyWeinberg equilibrium (HWE) and to compare the frequencies of hypertension, diabetes mellitus and smoking between groups. Differences in serum levels for the lipid profile were compared between groups by the $t$-test. The odds ratio was calculated as an estimate of the relative risk with a $95 \%$ confidence interval to assess the association between the $\varepsilon 4$ allele and the lipid profile in patients and controls. $\mathrm{P}<0.05$ was considered to be significant.

\section{Results}

\section{ApoE polymorphisms in CAD and non-CAD} subjects

The $\varepsilon 3$ allele was the most common in both the CAD (0.87) and non-CAD (0.81) groups, followed by the $\varepsilon 4$ allele $(0.09$ and 0.14 , respectively) and the $\varepsilon 2$ allele $(0.035$ and 0.050 , respectively, Table 1 ). No differences in allelic distribution were identified with respect to gender or age ( $<60$ years and

\begin{tabular}{|c|c|c|c|c|}
\hline \multirow[b]{2}{*}{ Allele } & \multicolumn{2}{|c|}{$C A D$ group } & \multicolumn{2}{|c|}{ Non-CAD group } \\
\hline & $\mathrm{N}$ & Frequency & $\mathrm{N}$ & Frequency \\
\hline$\varepsilon 2$ & 7 & 0.035 & 10 & 0.050 \\
\hline$\varepsilon 3$ & 175 & 0.875 & 162 & 0.810 \\
\hline$\varepsilon 4$ & 18 & 0.090 & 28 & 0.140 \\
\hline Total & 200 & 1.000 & 200 & 1.000 \\
\hline Genotype & $\mathrm{N}$ & $\%$ & $\mathrm{~N}$ & $\%$ \\
\hline દ2/દ2 & 0 & 0 & 2 & 2 \\
\hline દ2/દ3 & 7 & 7 & 3 & 3 \\
\hline$\varepsilon 2 / \varepsilon 4$ & 0 & 0 & 3 & 3 \\
\hline$\varepsilon 3 / \varepsilon 3$ & 76 & 76 & 68 & 68 \\
\hline$\varepsilon 3 / \varepsilon 4$ & 16 & 16 & 23 & 23 \\
\hline$\varepsilon 4 / \varepsilon 4$ & 1 & 1 & 1 & 1 \\
\hline Total & 100 & 100 & 100 & 100 \\
\hline
\end{tabular}

$\mathrm{N}=$ number of individuals. There were no significant differences ( $P>0.05$, Fisher test). 
$\geq 60$ years) in either group (data not shown). For patients and controls, the most common genotypes were $\varepsilon 3 / \varepsilon 3$ (76 and $68 \%$, respectively) and $\varepsilon 3 / \varepsilon 4$ (16 and $23 \%$, respectively) (Table 1). There were no differences in allelic or genotypic frequencies between groups. The calculation performed to test HWE showed that the genotypic distribution in the CAD group was similar to that expected $\left(\chi_{3}^{2}\right.$ $=0.927 ; 0.80<\mathrm{P}<0.90)$. However, the nonCAD group showed departure from HWE, with a difference between the observed and expected genotypic proportions $\left(\chi_{3}^{2}=18.494\right.$; $\mathrm{P}<0.001)$.

\section{Lipid profile and risk factors}

There was a difference in the lipid profile of the CAD group compared to the nonCAD group (Table 2). The mean values for all the variables of the non-CAD group were within the recommended range, except for TG, and even then, with a lower mean value $(169.4 \pm 111.2 \mathrm{mg} / \mathrm{dL})$ compared to the CAD group $(230.5 \pm 163.1 \mathrm{mg} / \mathrm{dL} ; \mathrm{P}=0.010)$. The frequencies of hypertension, diabetes mellitus and smoking were 66, 29, and 59\%, respectively, for the CAD group and 28,10 , and $40 \%$, respectively, for the non-CAD group $(\mathrm{P}<0.05)$.

Table 2. Lipid profile of patients with obstructive coronary artery disease (CAD group) and controls (non-CAD group).

\begin{tabular}{lcc}
\hline $\begin{array}{l}\text { Lipid profile } \\
(\mathrm{mg} / \mathrm{dL})\end{array}$ & $\begin{array}{c}\text { CAD group } \\
(\mathrm{N}=100)\end{array}$ & $\begin{array}{c}\text { Non-CAD group } \\
(\mathrm{N}=100)\end{array}$ \\
\hline TC & $226.5 \pm 58.1$ & $194.8 \pm 51.1^{*}$ \\
LDLc $^{\text {a }}$ & $143.1 \pm 40.2$ & $113.4 \pm 38.6^{*}$ \\
HDLC & $36.3 \pm 12.1$ & $52.7 \pm 48.0^{*}$ \\
VLDLc ${ }^{\text {a }}$ & $34.4 \pm 16.9$ & $30.6 \pm 13.1$ \\
TG & $230.5 \pm 163.1$ & $169.4 \pm 111.2^{*}$
\end{tabular}

Data are reported as mean $\pm \mathrm{SD}$. TC $=$ total cholesterol; LDLC $=$ low-density lipoprotein cholesterol; HDLc = high-density lipoprotein cholesterol; $\mathrm{VLDLC}=$ very low-density lipoprotein cholesterol; $\mathrm{TG}=$ triglycerides. ${ }^{\mathrm{a}} \mathrm{N}=84$ patients and 96 controls.

${ }^{*} \mathrm{P}<0.05$ compared to the CAD group (Fisher test).
ApoE polymorphisms, lipid profile and risk factors

The association of the lipid profile with the apoE polymorphisms for the CAD and non-CAD groups observed by comparing genotypes with at least one $\varepsilon 4$ allele $(\varepsilon 4 / \varepsilon 4+$ $\varepsilon 3 / \varepsilon 4+\varepsilon 2 / \varepsilon 4)$ and those without the $\varepsilon 4$ allele is shown in Figure 1. The variations in the lipid profiles within each group with respect to the presence or absence of the $\varepsilon 4$ allele were similar. Nevertheless, the CAD group presented higher mean TC and LDLc values compared to the non-CAD group (recommended values) both with ( $\mathrm{P}=0.023$ and 0.004 , respectively) and without the $\varepsilon 4$ allele $(\mathrm{P}=0.007$ and 0.0001 , respectively). HDLc levels were lower in patients with the $\varepsilon 4$ allele compared to the non-CAD group $(35 \pm 11,51 \pm 24 \mathrm{mg} / \mathrm{dL} ; \mathrm{P}=0.025)$, and the values also differed between groups in the absence of the $\varepsilon 4$ allele $(\mathrm{P}<0.0001)$. For VLDLc, no difference was observed between groups, with both presenting recommended levels in the presence or absence of the $\varepsilon 4$ allele (data not shown). On the other hand, for TG levels, even though the mean value was higher in the CAD subgroup with the $\varepsilon 4$ allele, a difference was detected between groups only for the genotypes without the $\varepsilon 4$ allele $(\mathrm{P}=0.041)$.

Figure 2 shows the effect of the $\varepsilon 4$ allele on the CAD and non-CAD groups and the difference (in percentage) of the mean levels of TC, LDLc, HDLc, and TG between the subgroups with and without the $\varepsilon 4$ allele. Note that in the CAD group the mean levels of TC (an increase of $22 \mathrm{mg} / \mathrm{dL}$ ) and LDLc (an increase of $13 \mathrm{mg} / \mathrm{dL}$ ) were about $10 \%$ higher in the subgroup with the $\varepsilon 4$ allele, while in the non-CAD group the values were 3.1 and $4.3 \%$, respectively (increases of 6 and $5 \mathrm{mg} / \mathrm{dL}$, respectively). In the presence of the $\varepsilon 4$ allele, a higher value of $16.3 \%$ (an increase of $37 \mathrm{mg} / \mathrm{dL}$ ) was observed for TG in the CAD group, while in the non-CAD group there was a reduction of $2.2 \%$ (a drop 
of $4 \mathrm{mg} / \mathrm{dL})$. HDLc levels presented a reduction of $5 \%$ (a drop of $2 \mathrm{mg} / \mathrm{dL}$ ) in patients with the $\varepsilon 4$ allele and a $5.3 \%$ increase (an increase of $3 \mathrm{mg} / \mathrm{dL}$ ) in the non-CAD group. The odds ratio showed an increase in LDLc
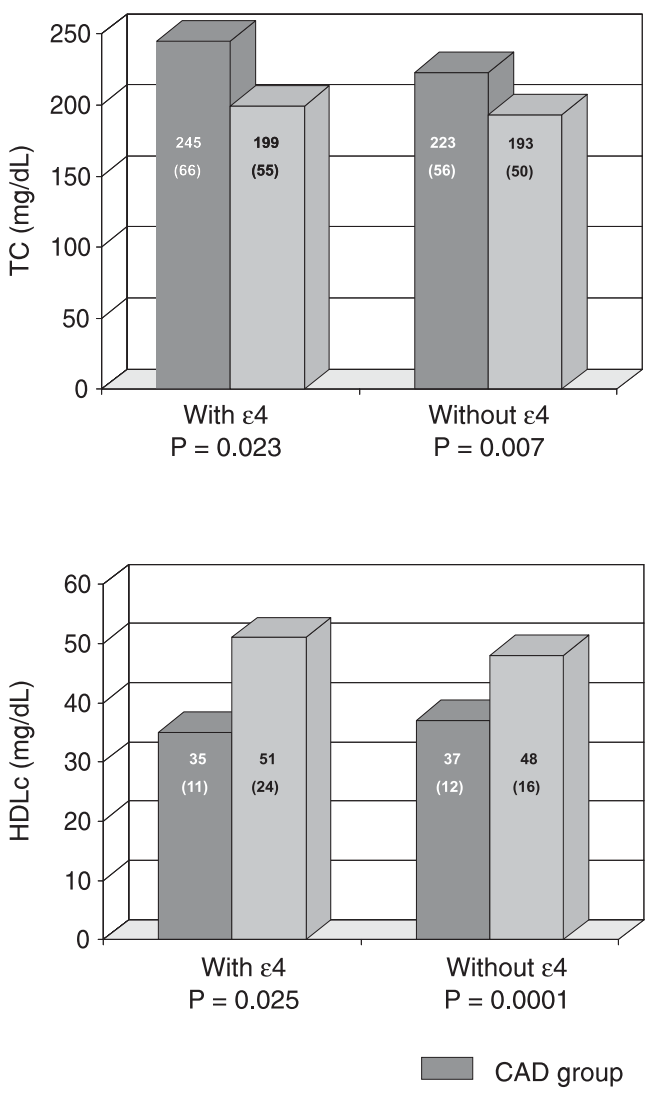

levels among individuals carrying the $\varepsilon 4$ allele in the non-CAD group (odds ratio = 2.531 ; confidence interval $=1.028-6.232$; Table 3).

An analysis of the apoE polymorphisms
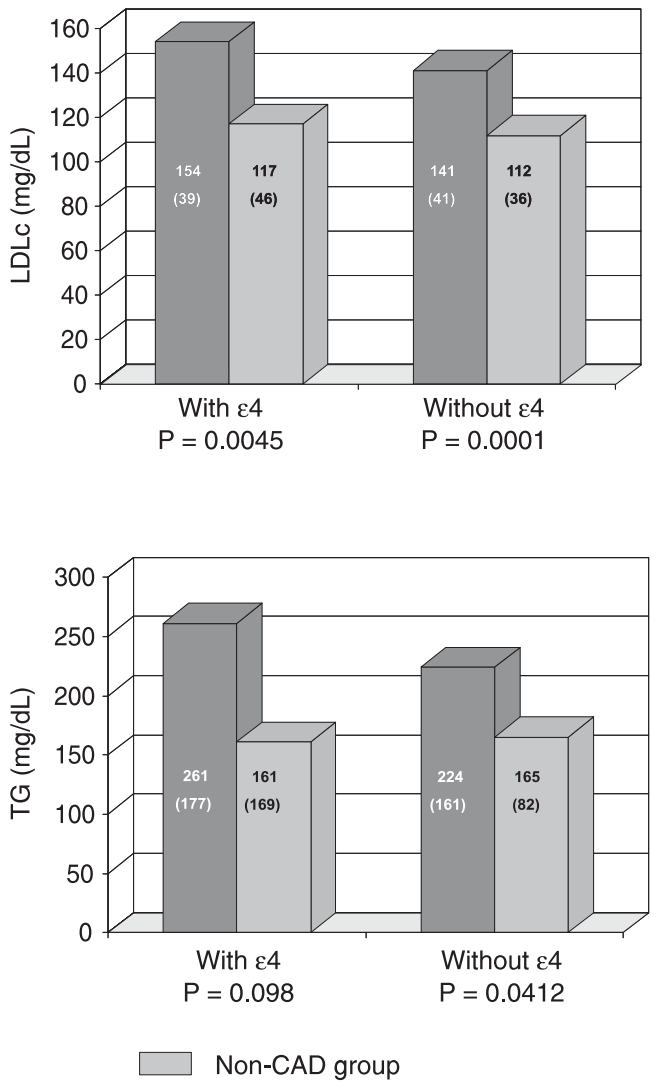

Figure 1. Total cholesterol (TC), low-density lipoprotein cholesterol (LDLC), high-density lipoprotein cholesterol (HDLC), and triglycerides (TG) in the presence or absence of the $\varepsilon 4$ allele of apolipoprotein $E$ in patients with coronary artery disease (CAD group) and controls (non-CAD group). Data are reported as means with SD reported in parentheses on each bar. Differences among the serum levels for the lipid profile between groups were not significant $(\mathrm{P}>0.05, t$-test $)$.

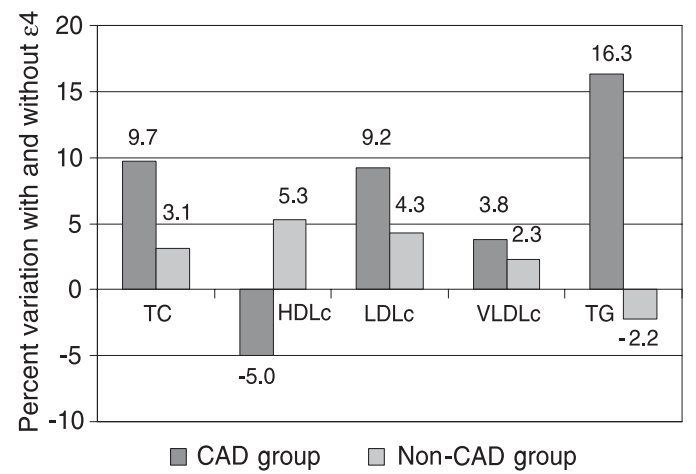

Figure 2. Effect of the $\varepsilon 4$ allele of apolipoprotein $E$ on the levels of total cholesterol (TC), low-density lipoprotein cholesterol (LDLC), high-density lipoprotein cholesterol (HDLC), very low-density lipoprotein cholesterol (VLDLC), and triglycerides (TG), considering the percent variation of the lipid profile in relation to the presence or absence of the $\varepsilon 4$ allele between patients with coronary artery disease (CAD group) and controls (non-CAD group). 
associated with hypertension and diabetes mellitus did not show differences between the groups regarding the allelic and genotypic distributions. There was no association between risk factors and presence of the $\varepsilon 4$ allele in either group or between this allele and increased LDLc levels in individuals with hypertension or diabetes mellitus. Also, no differences in sex or age were observed (data not shown).

\section{Discussion}

In the present study, the lower frequency of the $\varepsilon 4$ allele in patients with CAD suggests the absence of its association with the disease (16-18) in Brazilian patients, contrary to other reports on specific populations $(4,26)$. Moreover, the $\varepsilon 4$ allele seems not to influence the lipid profile in the $\mathrm{CAD}$ group (24-26), although these individuals present reduced levels of HDLc and increased levels of TC, LDLc, and TG, but also higher frequencies of the risk factors. On the other hand, the non-CAD group, with reduced frequencies of hypertension, diabetes mellitus and smoking compared to the CAD group, showed higher levels of LDLc associated with the $\varepsilon 4$ allele compared to the presence of $\varepsilon 3$. This reinforces the influence of the $\varepsilon 4$ allele on the lipid profile of the population, considering its action on the metabolism of serum lipids (3).
The genotypic distribution observed in the CAD group agreed with what was expected according to HWE. However, this did not occur in the non-CAD group. Other investigators have reported similar situations in case-control type studies with the analysis of single nucleotide polymorphisms, with a departure from HWE in patients or controls or in both groups $(5,27)$. In this case, apart from possible evolutive factors, the sample size, possible systemic errors while genotyping, failures while applying or interpreting the test, and even the adopted genetic disease model (dominant, recessive, additive, and multiplicative) should be considered (27). In addition, genes with late-onset manifestations may be simultaneously associated with other lethal diseases of earlier onset; the $\varepsilon 4$ allele of apoE is a known risk factor for acute myocardial infarction, stroke, and peripheral artery disease, among other diseases $(1,3,8,14)$. Hence, there is a competitive risk of death distancing HWE from more elderly control individuals. Likewise, selection of elderly individuals in itself favors the grouping of subjects with the $\varepsilon 2 / \varepsilon 2$ genotype in the non-CAD group, considering the protective effect of the $\varepsilon 2$ allele against CAD $(3,28)$.

In the present study, the allelic and genotypic distributions did not differentiate patients from controls. However, studies of younger populations, possibly under less in-

Table 3. Odds ratio for altered lipid profile according to the frequency of the $\varepsilon 4$ allele for apolipoprotein $E$ in patients with coronary artery disease (CAD group) and controls (non-CAD group).

\begin{tabular}{cccccc}
\hline \multirow{2}{*}{ Group } & \multicolumn{5}{c}{ Odds ratio $(\mathrm{Cl})$} \\
\cline { 2 - 6 } & TC & LDLC & HDLc & VLDLc & TG \\
\hline CAD & 2.039 & 2.276 & 0.8021 & 2.314 & 0.6042 \\
$95 \% \mathrm{Cl}$ & $(0.6112-6.804)$ & $(0.7524-6.884)$ & $(0.2471-2.603)$ & $(0.6521-8.213)$ & $(0.2106-1.734)$ \\
Non-CAD & 0.778 & $2.531^{*}$ & 0.3704 & 1.889 & 0.8462 \\
$95 \% \mathrm{Cl}$ & $(0.3181-1.092)$ & $(1.028-6.232)$ & $(0.1114-1.231)$ & $(0.7421-4.808)$ & $(0.3296-2.173)$ \\
\hline
\end{tabular}

$\mathrm{Cl}=$ confidence interval; TC = total cholesterol; LDLC = low-density lipoprotein cholesterol; HDLc = highdensity lipoprotein cholesterol; VLDLc = very low-density lipoprotein cholesterol; TG = triglycerides. *Higher frequency of increased LDLc levels in the non-CAD group $(P=0.0488)$. 
fluence of environmental factors, might more reliably demonstrate the effect of the apoE polymorphisms. Salazar et al. (4), in a study of Brazilian subjects, detected an association between CAD and the $\varepsilon 4$ allele. However, contrary to the current study, younger non-diabetic women $(48 \pm 9$ years $)$ were studied, with a frequency of 0.07 for the $\varepsilon 2$ allele, 0.70 for $\varepsilon 3$, and 0.23 for $\varepsilon 4$. Also a study on a Finnish population showed elevated levels of the $\varepsilon 4$ allele (0.32) associated with a higher risk of CAD (29). Moreover, Cumming and Robertson (6) reported in a Scottish population a lower mean age at the first infarction in men with the $\varepsilon 3 / \varepsilon 4$ genotype compared to the other genotypes. In contrast, Lenzen et al. (30) did not observe any difference in the apoE alleles and genotypes between survivors of acute myocardial infarction and a control group. Furthermore, studies of different populations including Chinese (15) and Italians (16) support the lack of association between the $\varepsilon 4$ allele and CAD.

Recently, a meta-analysis of apoE genotypes and the risk for CAD was performed, including 48 studies published from 1983 to 2003 (15,492 cases and 32,965 controls) mainly of European, North American and Asian populations suffering non-fatal or fatal myocardial infarctions and angiographically confirmed CAD. The study demonstrated a higher risk (42\%) for CAD in individuals with the $\varepsilon 4$ allele compared to those with the $\varepsilon 3 / \varepsilon 3$ genotype (5). The results are consistent with those reported previously by another meta-analysis that analyzed 14 studies (3087 cases and 7059 controls) including clinically or angiographically diagnosed CAD (7). These systematic reviews stated that inadequate statistical analysis, geographic and ethnic differences, gender, CAD, end points, study design, and potential geneenvironment interactions can contribute to the differences among authors.

There is also controversy with respect to the association of apoE genetic polymor- phisms with changes in the lipid profile of individuals with CAD. In the current study, this association was not confirmed even when only lipid and lipoprotein levels higher than borderline were considered (data not shown). Scuteri et al. (31), evaluating the $\varepsilon 4$ allele as an independent risk factor for coronary artery events in men only, did not observe this association with increased TC levels. Additionally, in Japanese individuals, although the $\varepsilon 4$ allele was two times more common in CAD patients (0.23) compared to controls (0.10), there was no impact of its effect on LDLc levels identifying it as an independent risk factor for the disease (32).

On the other hand, although not many, there are reports that the apoE alleles are genetic markers for dyslipidemia and CAD (33). Studies have estimated the impact of apoE polymorphisms on the levels of cholesterol and on the risk for CAD, showing that $7 \%$ of the variation in cholesterol levels is associated with the apoE gene but only $2.8 \%$ of the variation can be considered to represent a risk for $\mathrm{CAD}$, corresponding to a considerable contribution for a single genetic factor (3).

In the present study, patients with at least one $\varepsilon 4$ allele demonstrated a $10 \%$ increase in TC and LDLc levels and a $16 \%$ increase in TG levels. Corbo et al. (34) also did not observe an association of the $\varepsilon 4$ allele with increased LDLc levels in Italian individuals. However, male patients showed higher levels of TC and LDLc, in particular those with the $\varepsilon 3 / \varepsilon 4$ genotype compared to those with the $\varepsilon 3 / \varepsilon 3$ and $\varepsilon 3 / \varepsilon 2$ genotypes. In this case the particularities of the genetic and environmental factors of the population, as well as the age (35), were highlighted as possibly influencing the effect of the apoE genotypes on the lipid profile.

Lower cholesterol levels have been the target of secondary atherosclerosis prevention programs. In this way, an increase in serum lipid levels in $\varepsilon 4$ allele carriers, even if insignificant, might contribute to a less 
favorable clinical evolution compared to the patients with recommended cholesterol levels. Incidentally, studies with therapeutic interventions have demonstrated the benefit of reducing serum cholesterol levels. In these studies, a $10 \%$ reduction in TC levels reduced the risk of non-fatal myocardial infarction by $19 \%$, the risk of fatal infarction by $12 \%$, and both by $15 \%$ (36). Moreover, this disease may be aggravated by other risk factors related to the development of the atherosclerotic process such as hypertension, diabetes mellitus and smoking $(24,37)$, which in the present study were more common in the CAD group than in non-CAD group, although there was no association with apoE polymorphisms.

Mechanisms have been proposed to try to explain the association between apoE and atherosclerosis. In this way, it was recently reported that the action of apoE depends on gender and type of allele, on reverse cholesterol transport, on platelet aggregation, and on oxidative processes. These probably affect the overall atherogenic potential due to modulation of lipoprotein metabolism (9). Surprisingly, in an experiment with animals Raffai et al. (38) demonstrated the capacity of apoE to cause regression of atherosclero- sis independent of serum cholesterol levels. In this case, it is possible that a class of HDLcontaining apoE promotes the removal of cholesterol from the foam cells at the injury site. Moreover, endothelial dysfunction, also present, may be reversed by the high serum level of apoE associated with an increase in the production of nitric oxide in the arterial wall (38).

It is evident that the predisposition to a complex disease such as CAD is determined by multiple genetic and environmental factors, with the possibility that one gene locus could identify a subgroup of at-risk individuals being unlikely. Thus, the synergic effect between genetic polymorphisms might explain the variations in the lipid profile, including the association of apoE with angiotensinogen, apoB, LDL receptor, apoB signal peptide, and lipoprotein lipase $(39,40)$.

In this study the $\varepsilon 4$ allele did not act as a risk factor for CAD. Furthermore, variations in the lipid profile of patients seem to be independent of apoE polymorphisms. However, in the non-CAD group, the increased LDLc levels are associated with the $\varepsilon 4$ allele, while the frequency of other risk factors is reduced.

\section{References}

1. Davignon J, Cohn JS, Mabile L, Bernier L. Apolipoprotein E and atherosclerosis: insight from animal and human studies. Clin Chim Acta 1999; 286: 115-143.

2. Souza DR, de Godoy MR, Hotta J, Tajara EH, Brandao AC, Pinheiro JS, et al. Association of apolipoprotein E polymorphism in late-onset Alzheimer's disease and vascular dementia in Brazilians. Braz $J$ Med Biol Res 2003; 36: 919-923.

3. Davignon J, Gregg RE, Sing CF. Apolipoprotein E polymorphism and atherosclerosis. Arteriosclerosis 1988; 8: 1-21.

4. Salazar LA, Hirata MH, Giannini SD, Forti N, Diament J, Lima TM, et al. Seven DNA polymorphisms at the candidate genes of atherosclerosis in Brazilian women with angiographically documented coronary artery disease. Clin Chim Acta 2000; 300: 139-149.

5. Song Y, Stampfer MJ, Liu S. Meta-analysis: apolipoprotein E genotypes and risk for coronary heart disease. Ann Intern Med 2004; 141: 137-147.

6. Cumming AM, Robertson FW. Polymorphism at the apoprotein-E locus in relation to risk of coronary disease. Clin Genet 1984; 25 310-313.

7. Wilson PW, Schaefer EJ, Larson MG, Ordovas JM. Apolipoprotein E alleles and risk of coronary disease. A meta-analysis. Arterioscler Thromb Vasc Biol 1996; 16: 1250-1255.

8. McCarron MO, Delong D, Alberts MJ. APOE genotype as a risk factor for ischemic cerebrovascular disease: a meta-analysis. Neurology 1999; 53: 1308-1311.

9. Davignon J. Apolipoprotein $\mathrm{E}$ and atherosclerosis: beyond lipid effect. Arterioscler Thromb Vasc Biol 2005; 25: 267-269.

10. Wu LH, Wu JT, Hopkins P. Apolipoprotein E: laboratory determinations and clinical significance. In: Rifai N, Warnick GH, Dominiczak $\mathrm{MH}$ (Editors), Handbook of lipoprotein testing. Washington: AACC Press; 1997. p 598.

11. Lehtimaki T, Moilanen T, Nikkari T, Solakivi T, Porkka K, Ehnholm $\mathrm{C}$, et al. Regional differences in apolipoprotein $\mathrm{E}$ polymorphism in Finland. Ann Med 1991; 23: 61-66. 
12. Shaw JT, Tate J, Kesting JB, Marczak M, Berkholz JR, Lovelock PK, et al. Apolipoprotein $\mathrm{E}$ polymorphism in indigenous Australians: allelic frequencies and relationship with dyslipidaemia. Med J Aust 1999; 170: 161-164.

13. Frikke-Schmidt R, Wittrup $H H$, Tybjaerg-Hansen A, Meinertz $H$, Schnohr P, Nordestgaard BG. Apolipoprotein E genotypes predict attendance rates at lipid clinic. Atherosclerosis 2000; 153: 461-468.

14. Siest G, Pillot T, Regis-Bailly A, Leininger-Muller B, Steinmetz J, Galteau MM, et al. Apolipoprotein E: an important gene and protein to follow in laboratory medicine. Clin Chem 1995; 41: 1068-1086.

15. Cao W, Chen F, Teng L, Wang S, Fu S, Zhang G. The relationship between apolipoprotein $E$ gene polymorphism and coronary heart disease and arteriosclerotic cerebral infarction. Zhonghua Yi Xue Yi Chuan Xue Za Zhi 1999; 16: 249-251.

16. Scaglione L, Bergerone S, Gambino R, Imazio M, Macchia G, Cravetto A, et al. Role of lipid, apolipoprotein levels and apolipoprotein $\mathrm{E}$ genotype in young Italian patients with myocardial infarction. Nutr Metab Cardiovasc Dis 1999; 9: 118-124.

17. Pablos-Mendez A, Mayeux R, Ngai C, Shea S, Berglund L. Association of apo $\mathrm{E}$ polymorphism with plasma lipid levels in a multiethnic elderly population. Arterioscler Thromb Vasc Biol 1997; 17: 35343541.

18. Aguilar CA, Talavera G, Ordovas JM, Barriguete JA, Guillen LE, Leco ME, et al. The apolipoprotein E4 allele is not associated with an abnormal lipid profile in a Native American population following its traditional lifestyle. Atherosclerosis 1999; 142: 409-414.

19. Boudreau DA, Scheer WD, Malcom GT, Mulvad G, Pedersen HS, Jul E. Apolipoprotein E and atherosclerosis in Greenland Inuit. Atherosclerosis 1999; 145: 207-219.

20. Parra FC, Amado RC, Lambertucci JR, Rocha J, Antunes CM, Pena SD. Color and genomic ancestry in Brazilians. Proc Natl Acad Sci U $S$ A 2003; 100: 177-182.

21. Hixson JE, Vernier DT. Restriction isotyping of human apolipoprotein $\mathrm{E}$ by gene amplification and cleavage with Hhal. $J$ Lipid Res 1990; 31: 545-548.

22. Bucolo G, David H. Quantitative determination of serum triglycerides by the use of enzymes. Clin Chem 1973; 19: 476-482.

23. Trinder $P$. Determination of glucose in blood using glucose oxidase with an alternative oxygen acceptor. Ann Clin Biochem 1969; 6: 2427.

24. Santos RD. III Brazilian Guidelines on Dyslipidemias and Guideline of Atherosclerosis Prevention from Atherosclerosis Department of Sociedade Brasileira de Cardiologia. Arq Bras Cardiol 2001; 77 (Suppl 3): 1-48.

25. Report of the Expert Committee on the Diagnosis and Classification of Diabetes Mellitus. Diabetes Care 1997; 20: 1183-1197.

26. Lahoz C, Schaefer EJ, Cupples LA, Wilson PW, Levy D, Osgood D, et al. Apolipoprotein $\mathrm{E}$ genotype and cardiovascular disease in the Framingham Heart Study. Atherosclerosis 2001; 154: 529-537.
27. Wittke-Thompson JK, Pluzhnikov A, Cox NJ. Rational inferences about departures from Hardy-Weinberg equilibrium. Am J Hum Genet 2005; 76: 967-986.

28. Yang SL, He BX, Liu HL, He ZY, Zhang H, Luo JP, et al. Apolipoprotein $\mathrm{E}$ gene polymorphisms and risk for coronary artery disease in Chinese Xinjiang Uygur and Han population. Chin Med Sci J 2004; 19: 150-154.

29. Kuusi T, Nieminen MS, Ehnholm C, Yki-Jarvinen H, Valle M, Nikkila $\mathrm{EA}$, et al. Apoprotein $\mathrm{E}$ polymorphism and coronary artery disease. Increased prevalence of apolipoprotein E-4 in angiographically verified coronary patients. Arteriosclerosis 1989; 9: 237-241.

30. Lenzen HJ, Assmann G, Buchwalsky R, Schulte H. Association of apolipoprotein E polymorphism, low-density lipoprotein cholesterol, and coronary artery disease. Clin Chem 1986; 32: 778-781.

31. Scuteri A, Bos AJ, Zonderman AB, Brant LJ, Lakatta EG, Fleg JL. Is the apoE4 allele an independent predictor of coronary events? Am J Med 2001; 110: 28-32.

32. Dallongeville J, Lussier-Cacan S, Davignon J. Modulation of plasma triglyceride levels by apoE phenotype: a meta-analysis. J Lipid Res 1992; 33: 447-454.

33. Wilson PW, Myers RH, Larson MG, Ordovas JM, Wolf PA, Schaefer EJ. Apolipoprotein E alleles, dyslipidemia, and coronary heart disease. The Framingham Offspring Study. JAMA 1994; 272: 16661671.

34. Corbo RM, Vilardo T, Ruggeri M, Gemma AT, Scacchi R. Apolipoprotein $\mathrm{E}$ genotype and plasma levels in coronary artery disease. A case-control study in the Italian population. Clin Biochem 1999; 32: 217-222.

35. Jarvik GP, Goode EL, Austin MA, Auwerx J, Deeb S, Schellenberg $\mathrm{GD}$, et al. Evidence that the apolipoprotein E-genotype effects on lipid levels can change with age in males: a longitudinal analysis. Am J Hum Genet 1997; 61: 171-181.

36. Rossouw JE, Lewis B, Rifkind BM. The value of lowering cholesterol after myocardial infarction. N Engl J Med 1990; 323: 1112-1119.

37. Dominiczak MH. Review of international guidelines for the diagnosis and treatment of lipids disorders. In: Rifai N, Warnick GR, Dominiczak MH (Editors), Handbook of lipoprotein testing. 2nd edn. Washington: AACC Press; 2000. p 819.

38. Raffai RL, Loeb SM, Weisgraber $\mathrm{KH}$. Apolipoprotein $\mathrm{E}$ promotes the regression of atherosclerosis independently of lowering plasma cholesterol levels. Arterioscler Thromb Vasc Biol 2005; 25: 436-441.

39. Batalla A, Alvarez R, Reguero JR, Hevia S, Iglesias-Cubero G, Alvarez $\mathrm{V}$, et al. Synergistic effect between apolipoprotein $\mathrm{E}$ and angiotensinogen gene polymorphisms in the risk for early myocardial infarction. Clin Chem 2000; 46: 1910-1915.

40. Friedlander $\mathrm{Y}$, Leitersdorf $\mathrm{E}$, Vecsler $\mathrm{R}$, Funke $\mathrm{H}$, Kark J. The contribution of candidate genes to the response of plasma lipids and lipoproteins to dietary challenge. Atherosclerosis 2000; 152: 239248 